\title{
Diagnosis and Treatment of Vascular Surgery Related Infection
}

Yong-Gan Zhang ${ }^{*}$, Xue-Li Guo, Yan Song, Chao-Feng Miao, Chuang Zhang and Ning-Heng Chen

Department of Vascular Surgery, First Affiliated Hospital, Zhengzhou University, China

\begin{abstract}
Surgical site infection (SSI) is an important component of infections acquired from hospital. The most significant feature of vascular surgery different from other surgeries is frequent application of artificial grafts. Once SSI occurs after vascular operations with grafts, it might results in a serious disaster. Staphylococcus aureus and coagulase-negative Staphylococcus are the most common pathogenic bacteria for SSI after vascular surgery. Although SSI in vascular surgery often lacks of typical clinical characters, some clinical symptoms, laboratory data and certain imaging procedures may help to diagnose. In most cases of SSI after vascular procedures, the artificial grafts must be removed and sensitive antibiotics should be administered. However, for different cases, personalized management plan should be made depending on the severity and location of SSI.
\end{abstract}

Keywords: Antibiotics, diagnosis, infection, treatment, vascular surgery.

\section{INTRODUCTION}

Vascular surgery is a new interdisciplinary subject of medicine. Besides has the general characteristics of other surgical disciplines, vascular surgery is characterized in that a variety of artificial graft (artificial blood vessels, stents, stent grafts) are widely used in clinical. Most vascular surgical operation is clean operation, but the chance of infection is usually increased, due to the application of artificial graft, and that vascular surgery patients are often elderly, and may be combined with a variety of internal medicine diseases such as diabetes, hypertension and heart disease, immune disease, weak body resistance. Once surgical site infection (SSI) is induced, the consequences would be disastrous. It's not enough, sometimes, with antibiotic therapy alone for graft infection, and if necessary, removal of the infected vascular graft and revascularization pathway have to be operated [1-3], otherwise SSI can cause serious limb loss, organ failure, and even death.

\section{RISK FACTORS}

Staphylococcus aureus and coagulase-negative staphylococci are the most common pathogens of vascular surgery SSI. According to statistics, both early (within 4 months after operation) and late (more than 4 months after graft infection), one forth to a half risk is caused by Staphylococcus aureus, gram-negative bacteria, and fungal infections are rare, generally only occurs in immunosuppressed patients (Table 1) [2].

\subsection{Preoperative Pollution}

The epidermis is the main source of bacteria. The graft surface can be contaminated by microbe through the following 3 ways: (1) Through transplantation of direct planting.

*Address correspondence to this author at the Department of Vascular Surgery, First Affiliated Hospital, Zhengzhou University, China;

E-mail: zhangyongganli@sina.com
An important way for the occurrence of the operation process of bacteria; and sweat glands, lymph node contact; graft and artery wall lesions connected; intestinal grafts or exudate pollution, exposure to injury or open gastrointestinal or genitourinary tract. (2) Through the operation incision. (3) By blood or lymphatic spread.

Table 1. Binary logistic regression analysisa of factors associated with surgical wound infection after lower limb vascular surgery.

\begin{tabular}{|c|c|c|c|}
\hline Risk factor & OR & $\mathbf{9 5 \% ~ C I ~}$ & $\mathbf{p}$ \\
\hline \hline $\begin{array}{c}\mathrm{CFU} / \mathrm{mL}>155,000 \text { on the } \\
\text { second postoperative day }\end{array}$ & 5.97 & $1.67-21.42$ & .006 \\
\hline Diabetes & 4.77 & $1.46-15.55$ & .010 \\
\hline Elective redo surgery & 0.16 & $0.03-0.88$ & .035 \\
\hline Infra-inguinal surgery & 4.11 & $0.95-17.84$ & .059 \\
\hline Male gender & 4.41 & $0.90-21.71$ & .068 \\
\hline
\end{tabular}

Note . $\mathrm{OR}=$ odds ratio $\mathrm{CI}=$ confidence interval; $\mathrm{CFU}=$ colony-forming unit.

${ }^{\text {a }}$ Regression model with $\mathrm{CFU} / \mathrm{mL}>155,000$ on the second postoperative day, diabetes, elective redo surgery, infra-inguinal surgery, and sex as covariates.

\subsection{Bacteria Planting by Vascular Graft}

The spread of bacteria by hematogenous pathway and planted in the graft or endovascular stent graft infection occurred is a common cause, but it is a very important mechanism. The animal experiments, perfused $10^{7}$ colony forming units (CFUs) of Staphylococcus aureus, experimental animal almost $100 \%$ in postoperative graft infection [3] occurred. In elderly patients with vascular disease, vascular catheter insertion, urinary tract infection or infection of the tissues (pneumonia or infected foot ulcer) often become the source of graft bacteria, and the occurrence of postoperative graft 


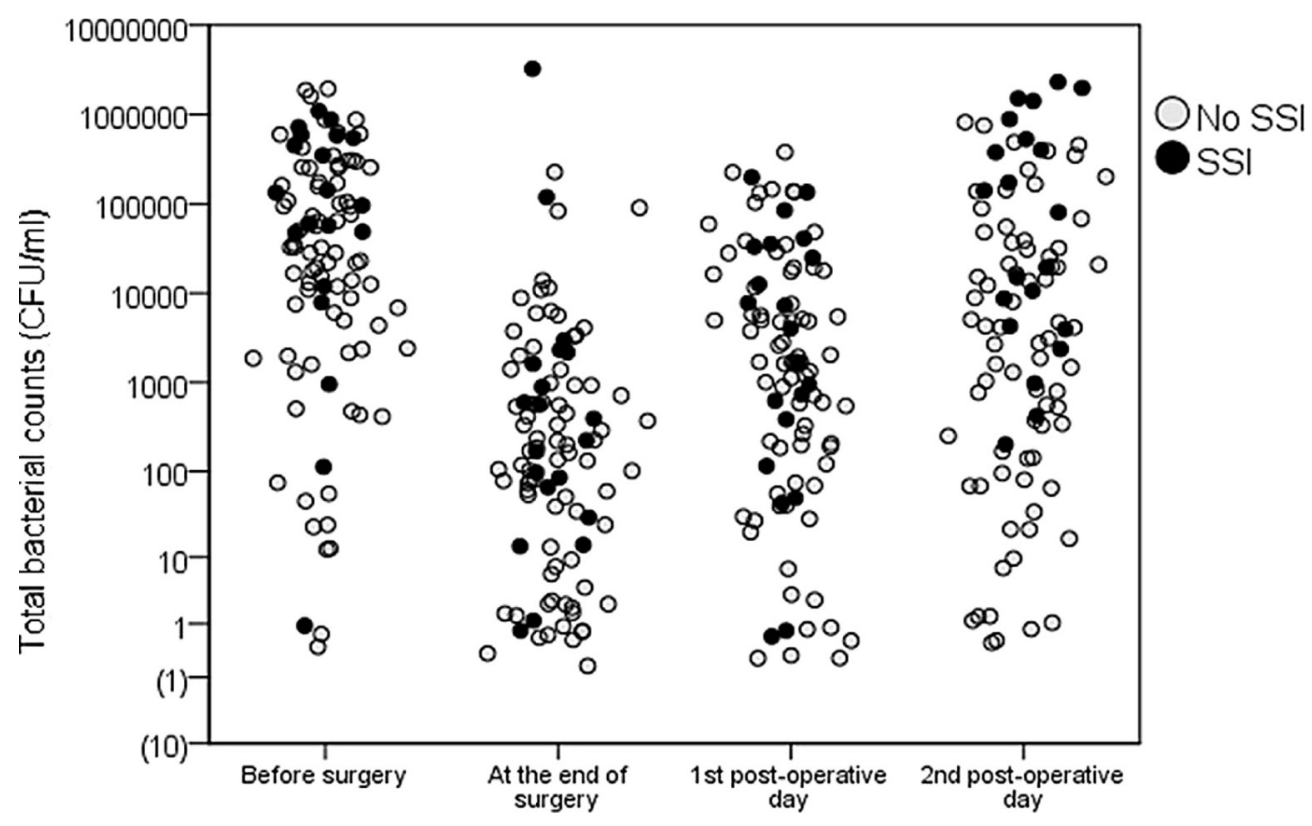

Fig. (1). Scatterplot of total bacterial counts (colony-forming units $/ \mathrm{mL}$ ) in patients with and without surgical site infection (y-axis in $\log _{10}$ scale). Note. $\mathrm{SSI}=$ surgical site infection.

infection [3]. After several years of operation, when the change in the immune system, causing vascular graft infection exists in the blood can be contaminated bacteria. Some people think, possible mechanism of late graft infection: for transplantation when vascular surface pathogenic bacteria [4] dormancy.

\subsection{Infection around Vascular Graft}

Because of the skin, gastrointestinal or genitourinary tract pollution, vascular graft infection can be caused around.

\section{DIAGNOSIS}

\subsection{Clinical Symptoms}

Vascular graft infection is lack of typical clinical manifestations, such as aortic graft infection, may be manifested as unexplained bacteremia, or simply manifested as abdominal distension and muscle tension; lower extremity, groin or neck vascular transplantation, if graft infection can appear to invade surrounding tissue, vascular grafts exposed around the tumor, wound drainage sinus formation or pulsatile anastomotic aneurysm. In short, as long as there are no signs suggesting vascular graft infection, should be further examined.

\subsection{Laboratory Tests}

Once the vascular graft infection, the patient may have inflammation phenomenon of fever, white blood cell counts increased, erythrocyte sedimentation rate higher nonspecific (Fig 1, Table 2) [2, 3]. Routine laboratory tests should include analysis of urine and blood culture, and of any possible sources of infection bacteria. But the patient laboratory only two thirds positive results, and the vessel of Staphylococcus epidermidis delayed periallograft infection, all laboratory results can be negative.
Table 2. Type and number of bacterial and fungal isolates recovered from 42 vascular surgical sites.

\begin{tabular}{|c|c|}
\hline Type & No. \\
\hline \multicolumn{2}{|l|}{ Gram-positive } \\
\hline \multicolumn{2}{|l|}{ Staphylococcus aureus } \\
\hline Methicillin-resistant & 10 \\
\hline Methicillin-sensitive & 5 \\
\hline S. epidermidis & 6 \\
\hline Enterococcus & 7 \\
\hline Streptococcus spp & 2 \\
\hline Methicillin-resistant S. epidermidis & 1 \\
\hline Vancomycin-resistant Enterococcus & 1 \\
\hline Bacteroides spp & 7 \\
\hline Total & 39 \\
\hline \multicolumn{2}{|l|}{ Gram-negative } \\
\hline Escherichia coli & 7 \\
\hline Pseudomonas & 3 \\
\hline Haemophilus & 1 \\
\hline Proteus & 1 \\
\hline Citrobacter & 1 \\
\hline Klebsiella & 1 \\
\hline Enterobacter & 2 \\
\hline Propionibacterium acnes & 2 \\
\hline Total & 18 \\
\hline Candida & 2 \\
\hline No growth & 2 \\
\hline
\end{tabular}




\subsection{Special Inspection Vessels}

Using vascular ultrasound, CT and MRI, can be detected in vascular plants infected graft shift caused by the abscess or anastomotic aneurysm, selective joint use of such special vascular examination, diagnosis of vascular graft infection sensitivity can reach more than $80 \%$, the specificity was $50 \%$ $\sim 90 \%$, and to help determine the surgical approach and the scope of 3; angiography in the planning of treatment has a guiding role; on suspicion of aortic graft infection patients must be two-way angiography, in order to understand the host and graft patency by the extent of infection and the proximal and distal vessels, in order to make further treatment.

\section{TREATMENT}

Without the use of artificial vascular surgical operation shift plant, the postoperative SSI treatment is same with other disciplines, including the principle of surgical debridement, washing, dressing and antibiotics when necessary. The use of artificial graft vascular surgical operation of plants, if SSI, has the special treatment, the standard surgical treatment plant blood vessel graft infection is: removal of the infected vascular graft, for extra anatomic bypass graft. But because of graft infection at different degree and scope, clinicians should according to the specific circumstances of vascular graft infection, to develop individualized treatment (Table 3) [1].

\subsection{Local Processing}

Local treatment of plant blood vessel graft infection includes transplantation of vascular bed to infection fully debridement and drainage, need debridement, remove of purulent necrotic tissue, and the persistent aortic stump debridement treatment. Positive vascular graft is an effective local treatment of retained vascular grafts, reduce the basis of amputation. Through effective treatment, $70 \%$ cases can be successfully preserved vascular graft [5-8].

Vascular graft infection is widespread or involving the anastomosis, artificial blood vessels should be removed, both ends of the artery by single strand suture. Persistent aortic wall and surrounding tissues, especially in the presence of suppurative change or pseudoaneurysm arterial wall, should debridement to normal form artery, artery stump covered with sterile tissue with activity. Artery debridement must be used to confirm the histological examination, such as arterial wall bacterial cultures were positive, need long-term antibiotic therapy.

The removal of residual bed infection of vascular graft, thoroughly debridement, removal of necrotic tissue purulent, until the normal tissue exposure, the wound, the closed negative pressure drainage tube, do sufficient drainage.

\subsection{Revascularization}

The occurrence of vascular graft infection, limb collateral circulation only when fully established, only consider the

Table 3. Predictors of cure at one year in $\mathbf{5 1}$ patients with aortic prosthetic vascular graft infections.

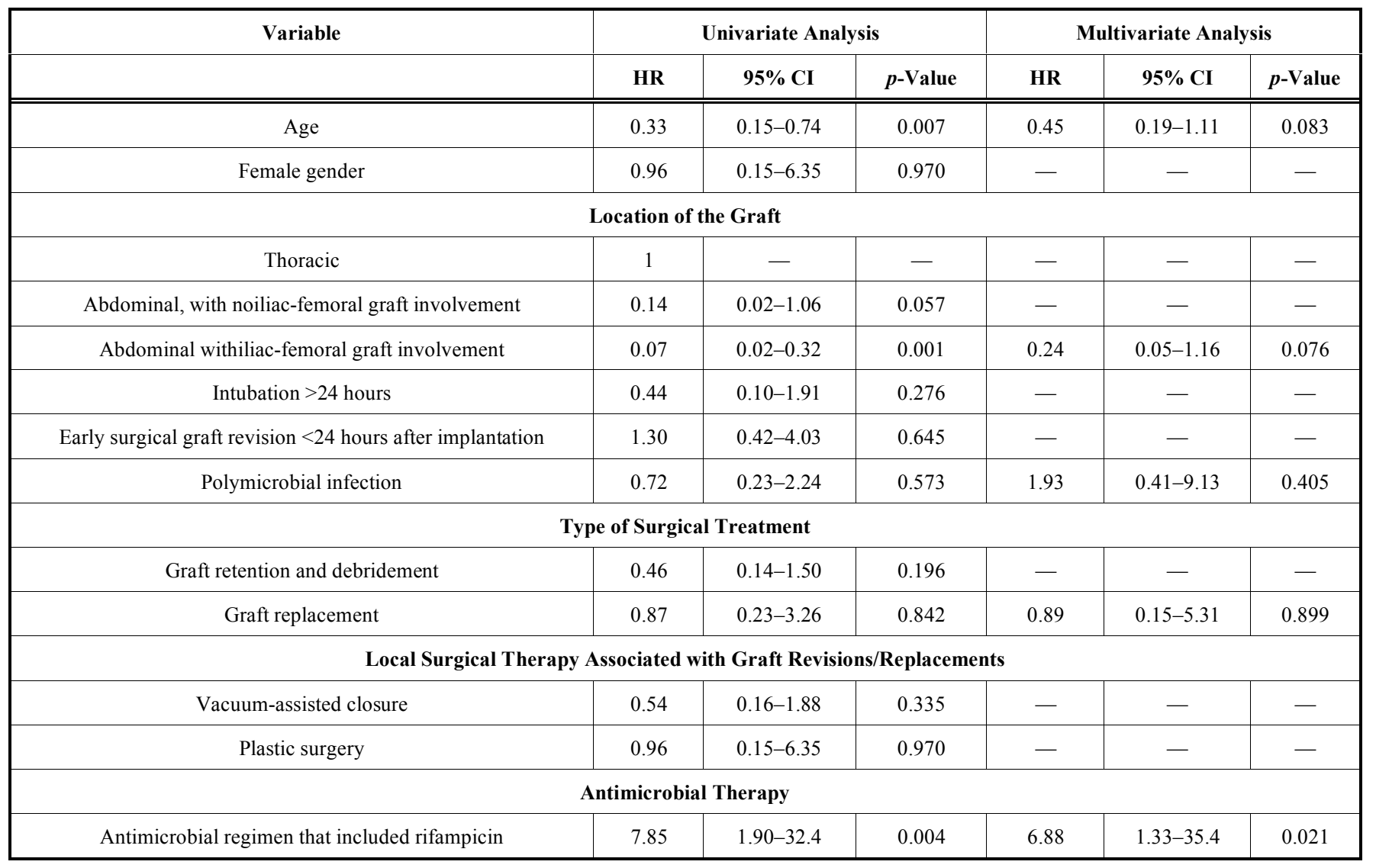


simple removal of infected vascular grafts, without vascular reconstruction. But such cases are rare, usually removed vascular grafts were performed after revascularization. The general remove of the infected vascular graft, the need for extra anatomic bypass grafting, in order to save the organs and limbs. After removal of the infected graft, in situ with autogenous vein, artery allograft or antibiotic containing artificial blood vessel revascularization, extra anatomic bypass graft compared with more standard, simplify the operation process, shorten the operation time, improve the superiority and graft patency rate. But for in situ vascular transplantation, prone to infection and infection of retransplantation vascular anastomosis, so only without systemic infection, and perivascular per gram of tissue culture of less than $10^{5}$ units (CFUs), cloning is possible in situ transplantation of blood vessel [9-11]. Revascularization of transplanted autologous vascular material selection is the best, followed by artificial blood vessel, but in most cases not suitable for autologous vascular graft, can only use artificial blood vessels, through normal tissue without bacterial infection is consistent with the normal host artery (Fig. 2) [1].

The general remove of the infected vascular graft, the need for extra anatomic bypass, in order to save the organs and limbs. The following is the classification of treatment according to different parts of the vascular graft infection.

\subsubsection{Aortic, Iliac Artery Vascular Graft Infection}

The aorta and iliac artery vascular graft infection, the most reasonable treatment principle is: first the right axillary artery to bilateral femoral artery bypass surgery; complete dissection, with sterile dressings covering all the wounds, and then open the complete removal of vascular graft infection. In extra anatomic revascularization, should be heparin therapy; artificial blood vessel and remove the infection, with heparin antagonists.

The extra anatomic bypass surgery and postoperative complications, statistical data shows that: the operation mortality was $11 \% \sim 27 \%$, the amputation rate occurred as
$9 \% \sim 27 \%[12,13]$, so as to have allogeneic vascular grafts, may be considered for in situ revascularization, can significantly reduce postoperative complications. But most of the medical institutions are unconditional access to these vessels.

\subsubsection{Aorta Bilateral Femoral Artery Vascular Graft Infec- tion}

Aorta bilateral femoral artery graft infection treatment is difficult, because the inguinal region of vascular graft infection, affect the lower limb blood supply, for extra anatomic bypass reconstruction, the distal anastomosis should be built in the deep femoral artery or superficial femoral artery to artery, even, in order to avoid the occurrence of lower extremity ischemic necrosis. The graft should choose diameter greater than $5 \mathrm{~mm}$ or PTFE artificial blood vessels of saphenous vein.

Occurred in the late postoperative and localized in the inguinal region of vascular graft infection, can be considered part of the partial resection of the infected vessels, after thorough debridement, in situ revascularization; postoperative intravenous antibiotics for $2 \sim 4$ weeks, and continued to take 3 months.

\subsubsection{Femoral and Tibial Artery Vascular Graft Infection}

Inguinales artificial vascular bypass vascular graft infection, are generally required to remove the artificial blood vessel. The treatment should follow the principle of treatment of vascular aortic graft infection, although the mortality rate is low, but the possibility of amputation is higher than $50 \%$ [14-17].

Such as the removal of the infected vessels, ankle arterial pressure or forearm pressure greater than $40 \mathrm{mmHg}$ $(1 \mathrm{mmHg}=0.133 \mathrm{kPa})$, suggesting that body can delay the establishment of collateral circulation, graft revascularization, and anti-inflammatory treatment, control of infection after revascularization, again to increase vascular grafting patency rate, reduce complications.

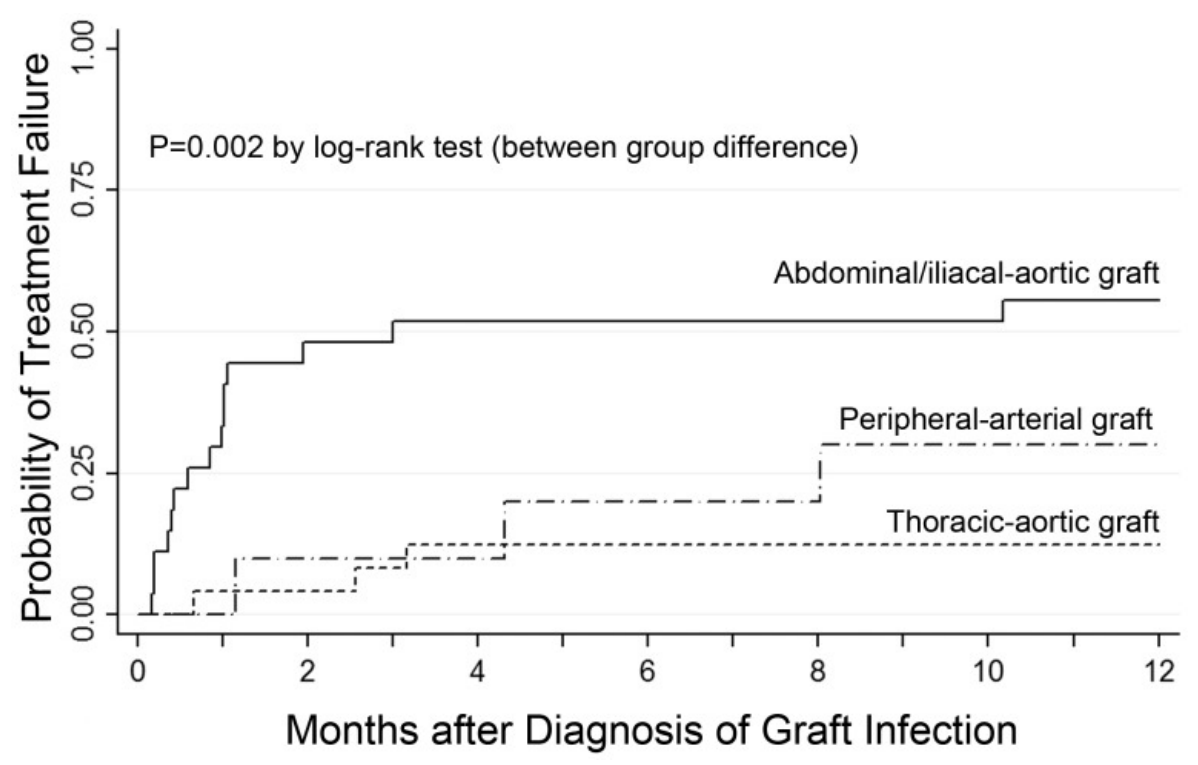

Fig. (2). Comparison of time to treatment failure in different types of prosthetic vascular graft infections. infections are compared with respect to the location of the prosthetic vascular graft using kaplan-meier estimates. 


\subsubsection{Innominate Artery, Subclavian Artery and Carotid Artery Vascular Graft Infection}

Intrathoracic vascular graft infection, the treatment principle is: to remove the entire graft, vascular reconstruction with autologous vascular graft materials as much as possible, and intravenous injection of antibiotics. The remove of grafts, in order to control the proximal vessels, often require incision and median clavicle, cardiopulmonary bypass.

Because the upper limb ischemia underwent transthoracic or extrathoracic bypass surgery, and the occurrence of vascular graft infection, resection of the infected vascular graft, generally do not need immediate revascularization; because the upper limb necrosis due to ischemia and rarely occur. Re revascularization in complete control after infection, and can increase the success rate of transplantation operation.

Carotid artery bypass vascular graft infection, artery ligation in general can't tolerate simple, only when the carotid stump pressure is greater than $70 \mathrm{mmHg}$, it can only simple ligation of common carotid artery and internal carotid artery [18]. But in order to ensure the blood perfusion of cerebral circulation, prevent the occurrence of shock, it should be possible for revascularization.

Carotid endarterectomy artificial patch infection, should be artificial patch resection of the carotid artery, using autologous vascular patch, in the process of operation, the carotid artery bypass is safe and effective measures of cerebral blood flow.

\subsubsection{Stents and Endovascular Infection}

The endovascular exclusion in the surgical trauma, the intestinal tract and other organs significantly reduce interference, shorten the operation time, intraoperative and postoperative blood transfusion without the above factors, significantly reduce the chance of graft infection. Therefore, intraluminal vascular graft infections are more rare. But the endoscopic operation of complex technology and instruments are more numerous, the need for surgery in the DSA, so as to increase the chance of graft infection. Once the endovascular graft infection, often associated with sepsis and infection of the aneurysm and thrombus shedding bacteria, the most common pathogenic bacteria were Staphylococcus aureus, artery plants and infection involving the shift treatment including removal of the cavity, parallel extra anatomic bypass, according to different parts of the vascular graft infection. Select the vascular reconstruction schemes of different [19].

\section{CONCLUSION}

Antibiotic-loaded PMMA beads may serve as an adjunct in the management of VSSIs and may also expand treatment options for graft preservation or in situ reconstruction, with expected recurrent infection rate approaching $20 \%$. Further experience with this adjunct may help elucidate its role in the management of this complicated problem, including the need for bead exchanges, until perigraft cultures are free of microbes.

\section{CONFLICT OF INTEREST}

The authors confirm that this article content has no conflict of interest.

\section{ACKNOWLEDGEMENTS}

Declared none.

\section{REFERENCES}

[1] S. Erb, J.A. Sidler, L. Elzi, L. Gurke, M. Battegay, A.F. Widmer, and M. Weisser, "Surgical and antimicrobial treatment of prosthetic vascular graft infections at different surgical sites: a retrospective study of treatment outcomes," PLoS One, vol. 9, no. 11, 2014.

[2] J. Turtiainen, T. Hakala, T. Hakkarainen, and J. Karhukorpi, "The impact of surgical wound bacterial colonization on the incidence of surgical site infection after lower limb vascular surgery: a prospective observational study," European Journal of Vascular and Endovascular Surgery, vol. 47, no. 4, pp. 411-417, 2014.

[3] P.A. Stone, A.Y. Mousa, S.M. Hass, D.D. Dearing, J.R. Campbell, A. Parker, S. Thompson, and A.F. AbuRahma, "Antibiotic-loaded polymethylmethacrylate beads for the treatment of extracavitary vascular surgical site infections," Journal of Vascular Surgery, vol. 55, no. 6, pp. 1706-1711, 2012.

[4] W.W. Wu, and C.W. Liu, "Diagnosis and treatment of surgical site infection in vascular surgery," Chinese Journal of Practical Surgery, vol. 31, no. 12, pp. 1077-1080, 2011. (in Chinese)

[5] M.S. Calderwood, A. Ma, Y.M. Khan, M.A. Olsen, D.W. Bratzler, D.S. Yokoe, D.C. Hooper, K. Stevenson, V.J. Fraser, R. Platt, and S.S. Huang, "CDC Prevention Epicenters Program. Use of Medicare diagnosis and procedure codes to improve detection of surgical site infections following hip arthroplasty, knee arthroplasty, and vascular surgery," Infection Control and Hospital Epidemiology, vol. 33, no. 1, pp. 40-49, 2012.

[6] J. Amour, A. Birenbaum, O. Langeron, M. Y. Le, M. Bertrand, P. Coriat, B. Riou, M. Bernard, and P. Hausfater, "Influence of renal dysfunction on the accuracy of procalcitonin for the diagnosis of postoperative infection after vascular surgery," Critical Care Medicine, vol. 36, no. 4, pp. 1147-1154, 2008.

[7] C.E.P.C. Almeida, L. Reis, L. Carvalho, and C.M.C. Almeida, "Collagen implant with gentamicin sulphate reduces surgical site infection in vascular surgery: a prospective cohort study," International Journal of Surgery, vol. 12, no. 10, pp. 1100-1104, 2014.

[8] A. Ramcharan, J. Penders, E. Smeets, M. Rouflart, F. van Tiel, C. Bruggeman, C. Baeten, S. Breukink, J. Tordoir, and E. Stobberingh, "Cross-sectional study on surveillance of surgical site infections after vascular surgery," Future Microbiology vol. 8, no. 11, pp. 1373-1380, 2013.

[9] Z.Q. Xie, and W.Q. Peng, "Species and antimicrobial resistance of pathogenic bacteria causing surgical infections," Chinese Journal of Nosocomiology, vol. 23, no. 16, pp. 4264-4266, 2013.

[10] S.T. Hussain, "Local application of gentamicin-containing collagen implant in the prophylaxis and treatment of surgical site infection following vascular surgery," International Journal of Surgery, vol. 10, no. 1, pp. S5-S9, 2012.

[11] J. Turtiainen, and T. Hakala, "Surgical wound infections after peripheral vascular surgery," Scandinavian Journal of Surgery, vol. 103, no. 4, pp. 226-231, 2014.

[12] S.J. Liu, C.X. Yin, M.C. Ding, and Y.Z. Wang, "Distribution and drug resistance of pathogens causing surgical incision infections in vascular surgery department," Chinese Journal of Nosocomiology, vol. 24, no. 17, pp. 4295-4297, 2014.

[13] L. Neumayer, P. Hosokawa, K. Itani, M. El-Tamer, W.G. Henderson, and S.F. Khuri, "Multivariable predictors of postoperative surgical site infection after general and vascular surgery: results from the patient safety in surgery study," Journal of the American College of Surgeons, vol. 204, no. 6, pp. 1178-1187, 2007.

[14] M. Mirzaie, J.D. Schmitto, T. Tirilomis, S. Fatehpur, O.J. Liakopoulos, N. Teucher, H. Durge, and F.A. Schendube, "Surgical management of vascular graft infection in severely ill patients by partial resection of the infected prosthesis," European Journal of Vascular and Endovascular Surgery, vol. 33, no. 5, pp. 610-613, 2007.

[15] S. Homer-Vanniasinkam, "Surgical site and vascular infections: treatment and prophylaxis," International Journal of Infectious Diseases, vol. 11, no. 1, pp. S17-S22, 2007.

[16] E. Frei, K. Hodgkiss-Harlow, P.J. Rossi, C. E. Jr. Edmiston, and D.F. Bandyk, "Microbial pathogenesis of bacterial biofilms: a 
causative factor of vascular surgical site infection," Vascular and Endovascular Surgery, vol. 45, no. 8, pp. 688-696, 2011.

[17] J. van der Slegt, J. A. J. W. Kluytmans, P. G. H. Mulder, E. J. Veen, G. H. Ho, and L. van der Laan, "Surgical site infection after multiple groin incisions in peripheral vascular surgery," Surgical Infections, vol. 15, no. 6, pp. 752-756, 2014.

[18] A. Dua, S.S. Desai, G.R. Seabrook, K.R. Brown, B.D. Lewis, P.J. Rossi, C.E. Edmiston, and C.J. Lee, "The effect of surgical care improvement project measures on national trends on surgical site infections in open vascular procedures," Journal of Vascular Surgery, vol. 60, no. 6, pp. 1635-1639, 2014.

[19] E. Ott, F.C. Bange, D. Sohr, O. Teebken, and F. Mattner, "Risk factors associated with surgical site infections following vascular surgery at a German university hospital," Epidemiology and Infection, vol. 141, no. 6, pp. 1207-1213, 2013.

Received: May 26, 2015

Revised: July 14, 2015

Accepted: August 10, 2015

(C) Zhang et al.; Licensee Bentham Open.

This is an open access article licensed under the terms of the (https://creativecommons.org/licenses/by/4.0/legalcode), which permits unrestricted, noncommercial use, distribution and reproduction in any medium, provided the work is properly cited. 